\title{
Research on Training Mode of Art and Design "Modern Mentoring" Application Technological Talents
}

\author{
Hao Xiaohua \\ Guangzhou Industrial and Commercial College, \\ Guangdong ,Guangzhou, 510850 \\ Mail:21431031@qq.com
}

\begin{abstract}
Keywords: Application Technological; Modern Mentoring; School-Enterprise Cooperation; Production Religions; Art and Design
\end{abstract}

\begin{abstract}
Application of technical colleges and enterprises to carry out in-depth training mode, all universities are exploring and try paper case "modern mentoring" operation, describes the standards applied talents, the modern mentoring teaching role and try the case the effect of the applied talents cultivation mode, providing a new way of thinking.
\end{abstract}

\section{Theoretical Introduction of Background}

The 2014 China Development Forum, Vice Minister of Education Lu Xin pointed out after nearly 700 "upgraded" in Local Universities will gradually transition in 2000, make modern vocational education, focus on training engineers, senior technicians, high-quality workers, etc. . Employment-oriented, from the education model, the education system training model, the implementation of modern vocational education system.

How to carry out applied technology research teaching talents, we should learn from success stories. Vocational education with Germany's "dual system" was most successful at the international level. However, due to China's national conditions, corporate participation in personnel training process less school-enterprise cooperation superficial, more important than form. The cooperation of school-enterprise it is currently a common problem encountered by many colleges and universities. We need to explore and verify in practice.

Guangzhou Industrial and Commercial College was near Shiling Leather City, the regional economic development. In recent years, the national brand development and business transformation, always on the lookout. How do we need to cultivate skilled talents, provide opportunities and challenges.

\section{Application Technology Talents Standards of Modern Vocational Education}

Application of modern vocational education and training technical personnel, including engineers, senior technicians, highly quality workers are three types of people, have the following characteristics together ${ }^{[1]}$. Fig. 1 shows technology talents standards.

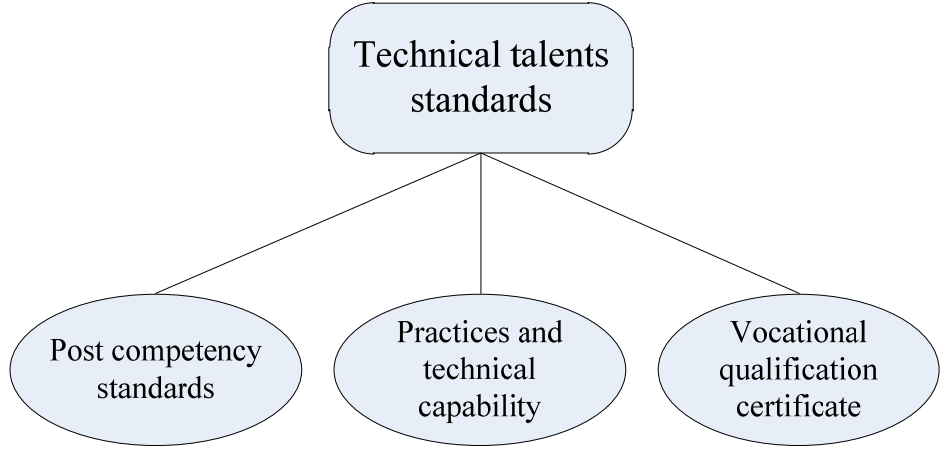

Fig. 1.The technology talents standards 
Capacity closer to the market standard job requirements, training design talents since employment-oriented, have the ability to know the needs of Index System positions. Set up professional courses, professional group of indicators for these capabilities. Such as leather goods design, the grid paper craft, sewing craft, board room production and other practical courses are job capacity requirements. Practical ability, technical experts are currently in urgent need of design education in universities and industry docking, design education needs to be a new training model, curriculum to address the needs of the future of China's manufacturing industry. For example, interior design courses, is an important design thinking, design or performance is more important. From the point of view of vocational education now, the design performance is more important. A fresh recruit, eat days.

Vocational qualification certificate as a sign skill level, professional competence based vocational skills certificates to job standards. Currently, we have adopted the arrangements for vocational qualification certificate system research program in practice, such as: CAD intermediate operator certificate, Photoshop senior operator certificate, $3 \mathrm{dmax}$ senior operator certificate.

\section{Modern Mentoring Teaching Mode}

How to Train Applied Technology Talents? First, there must have applied a highly skilled teaching team, the need to build a double-qualified teaching team, and through the establishment of school-enterprise cooperation mechanism, project-based, job skills teaching. And business exchanges learn from each other, co-education, to avoid the homogenization of culture, Health-oriented, split training, conduct Special Education, orientation training, and even one on counseling. Therefore, the "modern mentoring " Teaching is the trend ${ }^{[2]}$.

Apprenticeship in China has a long history and cultural traditions, the comic industry, music, drama circles, and martial arts have a rigorous apprenticeship culture, mostly family-owned, one rigorous training, success rate for the facade is in charge of carrying the family prosperous. And China's current vocational education, mostly "homogenization education", similar specialty, learned the same, but students learn more mediocrity, top-notch less diverted quit public. The implementation of modern teaching apprenticeship, outstanding personalized and Special Education, vocational colleges is the solution to "semi" of the good and the bad, the right medicine recipe. The implementation of "modern apprenticeship" There are many advantageous: Fig.2 shows function of modern mentoring teaching mode.

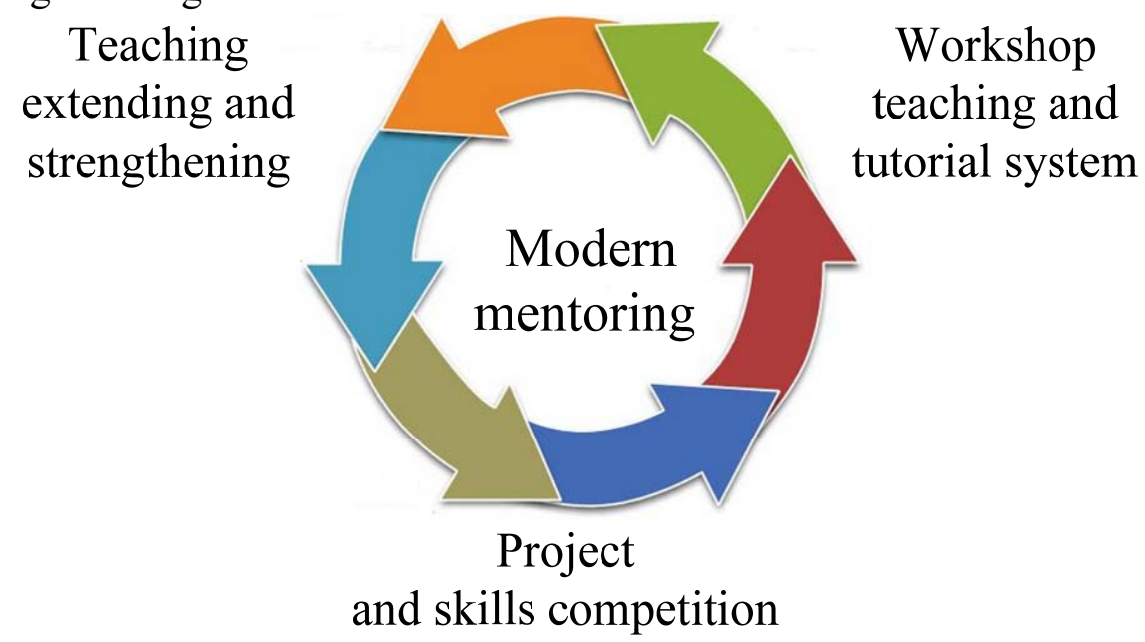

Fig. 2.The function of modern mentoring teaching mode

The extension and strengthening of practical courses for many teaching, the change of course, the skills and knowledge on a course to be easily forgotten. Teachers pay attention to the use of "student-centered" teaching method. Follow the selection of outstanding students into the teacher's interest groups, into the use of spare time enhance the training, through follow-up counseling, skills of students to consolidate and strengthen. "Project" + "Skills Competition" modern apprenticeship in the "division" is the best-qualified teacher double or double quality, practice ability, teaching in 
depth, the students attractive appeal, Morality excellent technical skills, in order to promote the apprenticeship students "Learning", "expand the depth." It can lead students to do the project, to participate in the skills competition and winning. He called a great day. Workshop Teaching and tutorial, mentoring by teaching studio system teaching, tutorial system to promote student education professionals, students experienced the basic course of the first year after the second year to enter the shunt professional direction of each project team, the same topic, different content. From start to finish, from the wide to narrow, from coarse to fine, implementation. Skilled professional stronger, more specialized, more competitive.

\section{Modern Mentoring Practice Cases}

Teaching practice, we also explore some of the practices of teaching apprenticeship and continuous improvement and development, specifically cited the following examples.

Pottery sculpture studio, "Clay model" professional art and design courses are required courses, practice animation role modeling through clay, sculpture, pottery, relief and other technical means, training of students modeling ability and creative innovation. In order to increase the students' creative ability, the 2014 college construction nearly 200 square meter training studio. Teachers are senior artists, and it is one of the 50 large sculpture divisions. After the normal teaching activities have been completed, the "apprenticeship" teaching methods, teaching practice into the studio one on one, make full use of spare time and weekends in the studio for creative works of design and production. His works have participated in various domestic and international competition events. Sculpture, clay creations gains awards. 2014 Sculpture Exhibition, Guangdong Province, three students won the provincial second prize, third prize good results. There are many pottery works through school-enterprise cooperation unit after burning finished products with high market value, which becomes a professional very loud card of art and design ${ }^{[3]}$.

Leather goods design studio - "pilot plant" expert leather Design Institute, learn German apprenticeship form plus China's national conditions, we can send business apprenticeship by teaching school practice to master the course. We design Leather Research Institute is school-enterprise cooperation unit of the Department of the Ministry, as the "pilot plant", the Institute hired craftsmen to relevant professional instructor training courses. In addition, the Guangdong Provincial Association of elite leather goods department and I have a close interaction. Association elite are executives and design director of various companies, the use of some design practice courses, hire them for apprenticeship education, in technology, technology production processes one guidance. In a paper handmade leather design grid, for example, professional courses teachers explained the theory part of the design, the practical operation of the links on the craftsmen practice instructor or an enterprise version of the master to complete education, cooperation between the two to complete four hours of the morning teaching implementation. Implementation of modern teaching apprenticeship. Teaching good results, students' enthusiasm

\section{Conclusions}

Through mentoring teaching practice, high gold content of the course allows students involvement and interest in learning greatly improved from the "want him to learn" to "I want to learn." Many students put their spare time cast in the studio, following the guidance of the teacher, to the time for work and skills. Obtain excellent results in more skills contest. It highlights the modern apprenticeship Teaching Mode effect on students. Throughout Undergraduate applications running technology-based education reform, the school-enterprise cooperation cooperative culture in an important position, is necessary as the basic model. Specific in-depth training model, companies need to increase participation in the practice of teaching to jointly develop teaching content, teaching methods using modern apprenticeship, personalized and Special Education, training of applied technology talents, It has practical significance, so as to cultivate the ground gas applied talents. 


\section{References}

[1] You Meiqin, modern apprenticeship and vocational school-based teachers' professional development, teachers Expo (scientific version), 2014, 5, 20.

[2] Cai Feng; Wang Gongming, arts and crafts modern apprenticeship training model to explore, study art education, 2013, 8, 15.

[3] Yi Bin, architectural high vocational education to explore the introduction of modern apprenticeship model, Guangxi Education, 2014, 12, 20. 